\title{
Prophylaxis of Venous Thromboembolism with Low Molecular Weight Heparin in Bariatric Surgery: a Prospective, Randomised Pilot Study Evaluating Two Doses of Parnaparin (BAFLUX Study)
}

\author{
Davide Imberti • Edoardo Baldini - Matteo Giorgi Pierfranceschi • \\ Alberto Nicolini • Concetto Cartelli • Marco De Paoli • Marcello Boni • \\ Esmeralda Filippucci • Stefano Cariani • Giorgio Bottani
}

Published online: 27 October 2013

(C) The Author(s) 2013. This article is published with open access at Springerlink.com

\begin{abstract}
Background The optimal dose of low molecular weight heparin (LMWH) to prevent venous thromboembolism (VTE) after bariatric surgery remains controversial. The aim of this multicentre, open-label, pilot study was to evaluate the efficacy and safety of two different doses of the LMWH parnaparin administered to patients undergoing bariatric surgery.

Methods Patients were randomised to receive 4,250 IU/day (group A) or 6,400 IU/day (group B) of parnaparin s.c. for 7-11 days. Bilateral colour Doppler ultrasound of the lower limb was performed before surgery and at the end of the treatment period. The primary efficacy outcome was a composite of asymptomatic and symptomatic deep vein
\end{abstract}

A complete list of the BAFLUX Investigators is provided in the Appendix.

D. Imberti $(\bowtie)$

Thrombosis Centre, Internal Medicine Department,

Piacenza Hospital, Via Taverna 49, 29100 Piacenza, Italy

e-mail: d.imberti@ausl.pc.it

E. Baldini

Dipartimento di Chirurgia, U.O. Chirurgia Generale, Piacenza, Italy

M. G. Pierfranceschi

Dipartimento di Emergenza, Ospedale G. Da Saliceto, Piacenza, Italy

\section{A. Nicolini}

Centro Emostasi e Trombosi, Medicina I, Azienda Ospedaliera

S. Maria Nuova, Reggio Emilia, Italy

C. Cartelli

Chirurgia Generale II, Azienda Ospedaliera S. Maria Nuova,

Reggio Emilia, Italy thrombosis, symptomatic pulmonary embolism and death from any cause during treatment. The primary safety endpoint was major and clinically relevant non-major bleeding.

Results A total of 258 patients underwent randomization; 8 subjects were excluded following the safety analysis. One hundred thirty-one patients [ 106 females; mean age, 40.3 years (standard deviation (SD) \pm 9.6 ); mean body mass index (BMI), $\left.44.6 \mathrm{~kg} / \mathrm{m}^{2}(\mathrm{SD} \pm 5.4)\right]$ were assigned to group $\mathrm{A}$ and 119 patients [ 93 females; mean age, 41.5 years ( $\mathrm{SD} \pm 9.9$ ); mean BMI, $\left.44.2 \mathrm{~kg} / \mathrm{m}^{2}(\mathrm{SD} \pm 5.4)\right]$ were assigned to group B. The rate of the primary efficacy outcome was $1.5 \%$ (two cases; $95 \%$ confidence interval $(\mathrm{CI}), 0.2-6.0 \%$ ) in group A as compared with $0.8 \%$ (one case; $95 \% \mathrm{CI}, 0.4-5.3 \%$ )

M. De Paoli

Chirurgia Generale, Ospedale Galliera, Genova, Italy

M. Boni

Chirurgia Generale, Foligno, Italy

E. Filippucci

U.O. Angiologia, Ospedale San Giovanni Battista, Foligno,

Perugia, Italy

S. Cariani

Centro Studi Obesità Patologica, Chirurgia Generale III,

Policlinico Sant'Orsola Malpighi, Bologna, Italy

G. Bottani

Dipartimento di Chirurgia Generale, Ospedale Civile Mortara, Pavia, Italy 
in group B $(p=n s)$. The composite incidence of major bleeding and clinically relevant non-major bleeding was $6.1 \%$ (eight cases; $95 \% \mathrm{CI}, 2.9-12.1 \%$ ) in group $\mathrm{A}$ and $5.0 \%$ (six cases; $95 \%$ CI, 2.1-11.1\%) in group B ( $p=\mathrm{ns}$ ). Conclusions A parnaparin dose of 4,250 IU/day seems suitable for VTE prevention in patients undergoing bariatric surgery.

Keywords Venous thromboembolism - Prophylaxis · Parnaparin $\cdot$ Bariatric surgery $\cdot$ Obesity

\section{Introduction}

Recent studies have shown that venous thromboembolism (VTE), including deep vein thrombosis (DVT) and pulmonary embolism (PE), is a significant and frequent complication after bariatric surgery [1-3]. Reported rates of post-operative DVT and/or PE range from 1 to $15 \%$ despite prophylaxis [4-6], and about $50 \%$ of deaths occurring in bariatric patients are attributed to a fatal PE [7]. Therefore, prevention of VTE is crucial in this clinical setting, and various regimens of low molecular weight heparin (LMWH) are used for perioperative thromboprophylaxis [8-14]. However, there are no clear guidelines regarding the optimal dosage of LMWH to prevent VTE in morbidly obese patients [2, 15, 16]. For example, Planes and colleagues have suggested that LMWHs should be used prophylactically at a fixed dose, independently of adjustments for body mass index (BMI) [17], while other papers have shown better efficacy using a higher dose of the drug in obese patients $[8,18]$. Studies evaluating the weightbased dosage of LMWH are limited, and criteria for dose adjustment in obese (BMI $>30 \mathrm{~kg} / \mathrm{m}^{2}$ ) and severely obese $\left(\mathrm{BMI}>50 \mathrm{~kg} / \mathrm{m}^{2}\right)$ patients remain controversial [19]. In particular, given that the intravascular volume does not have a linear relationship with body weight [20-22], it is possible that the use of weight-based dosing in obese patients could lead to overdosing; conversely, the use of a fixed thromboprophylactic dose could result in underdosing, while the safety and efficacy of a fixed intermediate dose have not been adequately investigated.

We therefore performed a pilot, randomised, controlled, open-label study evaluating efficacy and safety of a fixed prophylactic dose of parnaparin (4,250 IU/day) with a fixed intermediate dose of parnaparin $(6,400 \mathrm{IU} /$ day $)$ in obese patients undergoing bariatric surgery. Four thousand two hundred fifty international units per day of parnaparin is the recommended dose for the prevention of VTE in high-risk general surgery [23], while 6,400 IU/day is slightly higher than the $25 \%$ increase in the standard prophylactic dose suggested for severely obese patients at the consensus conference of the American College of Chest Physicians available when the study was planned [15].

\section{Materials and Methods}

\section{Patient Population}

Consecutive morbidly obese patients aged $>18$ years with a BMI $>36 \mathrm{~kg} / \mathrm{m}^{2}$ who were scheduled to undergo open and laparoscopic primary or revisional bariatric surgery under general anaesthesia at six Italian centres were eligible for inclusion. Exclusion criteria were as follows: presence of liver disease (acute and chronic hepatitis, cirrhosis, aminotransferases $>3$ times the normal upper limit); kidney disease (creatinine levels $>1.2 \mathrm{mg} / \mathrm{dL}$ ); platelet count $<100,000 / \mathrm{mm}^{3}$; documented history of DVT/ $\mathrm{PE}$ in the last 6 months; documented congenital/acquired coagulation disorders; concomitant anticoagulant/antiplatelet therapy for other risk factors; known hypersensitivity to heparin and derivatives; pregnancy; previous heparininduced thrombocytopenia; active peptic ulcer or known angiodysplasia of the colon, severe uncontrolled hypertension (systolic blood pressure $\geq 200 \mathrm{mmHg}$, diastolic $\geq 110 \mathrm{mmHg}$ ); previous haemorrhagic stroke, recent brain surgery ( $<3$ months from randomization), recent major bleeding ( $<3$ months of randomization), poor adherence to the study, withdrawal of informed consent; and participation in another clinical trial within the last 4 weeks or during the current trial.

The study was approved by the local ethics committees and written informed consent was obtained from all patients. The study was conducted according to the European Guidelines for Good Clinical Practice.

\section{Study Design}

BAFLUX is a prospective, randomised, open, pilot, controlled multicentre national study. Randomisation was balanced for sex and BMI ( $\leq 45$ and $>45 \mathrm{~kg} / \mathrm{m}^{2}$ ). A centralised blockbalanced randomisation plan was used, stratified by centre, gender and BMI. Eligible patients were randomised to receive 4,250 IU/day (group A) or 6,400 IU/day (group B) of subcutaneous parnaparin (Alfa Wassermann, Bologna, Italy) starting $12 \mathrm{~h}$ preoperatively, the second dose $24 \mathrm{~h}$ later and in any case at least $6 \mathrm{~h}$ after the closure of the surgical wound, once adequate hemostasis has been achieved. Subsequent injections were performed once a day for a period of $9 \pm 2$ days. Where the patient was discharged prior to completion of the treatment, the treatment was completed at home.

Patients were recommended to use graduated compression stockings and intermittent pneumatic compression; early deambulation was strongly encouraged.

Visit 1 was planned at the moment of patient recruitment, visit 2 at the end of the drug administration period (day 9 \pm 2 ) and visit 3 and visit 4 after 1 and 3 months of follow-up, 
respectively. A mandatory bilateral colour Doppler ultrasound of the lower limb venous system was performed in each patient before surgery and within $24 \mathrm{~h}$ of the end of the treatment period ( $9 \pm 2$ days).

At visits 1 and 2, the following blood chemistry exams were performed: prothrombin time (PT), activated partial thromboplastin time (aPTT), fibrinogen, creatinine, aminotransferases, haemoglobin level, glucose levels, urine output and platelet count. Pregnancy was excluded in fertile women patients using the Gravindex test.

The primary efficacy endpoint was the combination of the following VTE events occurring within $9( \pm 2)$ days: detection of asymptomatic DVT by colour Doppler ultrasound performed at the end of treatment (days 7-11), onset of symptomatic DVT and/or symptomatic pulmonary embolism (EP) (whether fatal or not) during the treatment period (with instrumental confirmation) and death from any cause. Secondary efficacy endpoints include each of the above thrombotic events occurring individually: all DVTs, all proximal DVTs, all isolated distal DVTs, non-fatal and fatal PEs. In addition, symptomatic DVTs and PEs recorded during the follow-up were secondary endpoints. The primary safety endpoint was the combination of major bleeding and clinically relevant non-major bleeding recorded between the first administration of the drug until 2 days after the last injection. Major bleeding is defined as fatal bleeding, bleeding in vital organs (intracranial, intraspinal, retroperitoneal, intraarticular, pericardial, intraocular); bleeding at the surgical site requiring reoperation; and bleeding associated with a reduction in $\mathrm{Hb}$ of at least $2 \mathrm{~g} / \mathrm{dL}$ or requiring transfusion of at least 2 units of packed red cells/whole blood. Bleeding was defined as clinically relevant if it was overt but did not meet the other criteria for major bleeding. Secondary safety endpoints are the incidence of adverse events and thrombocytopenia. Thrombocytopenia was defined as a $50 \%$ reduction in platelet count or less than $100,000 \mathrm{~mm}^{3}$. Heparin-induced thrombocytopenia (HIT) was diagnosed according to the combination of pre-test probability (4T score) and laboratory tests showing anti-heparin-PF4 complex antibodies [24].

After inclusion in the BAFLUX Study, any sign or symptom suggestive for VTE or bleeding during the treatment period was reported. In case of clinical suspicion of DVT or PE, an objective imaging testing was required to confirm the diagnosis (for DVT: compressive ultrasonography, colour Doppler ultrasound, computed tomography scan, venography; for PE: perfusion lung scan matched with chest X-ray, ventilation/perfusion scan, computed tomography, angiography). In case of bleeding, blood count, PT, aPTT and fibrinogen had to be performed, while any other diagnostic and therapeutic measurements that the investigator considered appropriate were recorded (e.g. radiology, endoscopy, etc.). A central committee whose members were not involved in patient recruitment and were unaware of any information regarding the patients (i.e. study group assignments, risk factors for VTE or bleeding) adjudicated the results of all suspected outcome events on the basis of clinical reports or hospital discharge letters sent in by the centres. In case of patient death, date and cause were registered.

\section{Ultrasound Examination}

A $7.5-10-\mathrm{MHz}$ linear ultrasound probe and a $3.5-5-\mathrm{MHz}$ convex probe were used. The examination was performed with the patient in a supine position and horizontal dorsal decubitus for the study of the femoral vein segments and in a seated position for the study of the popliteal, tibial, fibular and calf muscular vein segments. All venous segments of the lower limbs, from the groin to the ankle, with colour Doppler ultrasound and a compression manoeuvre were evaluated. Detection of venous flow was performed using spectral and coloured Doppler. The exam studied the following venous segments: femoral, ramified segment of the deep femoral, popliteal, posterior and anterior tibial, fibular and calf muscular veins. The noncompressibility of the vessel, the presence of hypoecogenic image, the absence of spontaneous and phasic flow during breathing and the nonincrease in flow during distal compression of the studied vessel were all interpreted as positive signs of lower limb DVT. The colour Doppler ultrasound test was performed by clinicians blinded to the dose of parnaparin given to the patients.

\section{Statistical Analysis}

Since this was a pilot study, no formal calculation of sample size was performed. During this exploratory phase, it was considered sufficient to enroll at least 100 patients per group (200 patients in total). The demographic and clinical data were summarised using frequency tables, or central tendency and dispersion tables, using the most appropriate indicators for the actual distribution of the individual variables (mean, standard deviation, minimum and maximum values observed). In order to evaluate the differences between groups, in the case of nominal variables, the Pearson $\chi$-squared test was applied, while for continuous type variables, we used the $t$ test for independent samples when comparing groups and the $t$ test for dependent samples to analyse pre/post-treatment variations within the same group; $p$ values $<0.05$ were considered significant. Statistical analysis was performed using the SPSS Statistical Package, ver. 15.0 software.

\section{Results}

Between April 2004 and February 2012, 258 consecutive morbidly obese patients (BMI $>36$ ) undergoing bariatric 
surgery were enrolled in this study. Eight subjects were not evaluable for the safety analysis for the following reasons: withdrawal of informed consent [1], refusing surgery [4] and inclusion criteria not met [3]. Of the 250 evaluable patients, 51 were males and 199 females with an age ranging from 18 to 64 , mean $40.9 \mathrm{SD} \pm 9.7$ years, with a BMI range of 36.1-64.1 and mean $44.4 \mathrm{SD} \pm 5.4 \mathrm{~kg} / \mathrm{m}^{2}$.

Baseline characteristics of the patients are reported in Table 1, while risk factors for VTE and concomitant disease are shown in Table 2; no statistically significant differences were found between the two groups. After randomisation, 131 patients received 4,250 IU parnaparin/day (group A) and 119 patients received 6,400 IU parnaparin/day (group B); elastic stockings were used in 224 patients (89.6\%), intermittent pneumatic compression in 155 patients $(62,0 \%)$, early deambulation in 241 patients $(96.4 \%)$ and electrical stimulation in 3 patients (Table 3 ).

Bariatric procedures per treatment group are described in Table 1. Preoperatively, no patients showed abnormal ultrasound results at the colour Doppler ultrasound examination.

During the treatment period, there were two $(1.5 \% ; 95 \%$ confidence interval (CI), 0.2-6.0\%) VTE complications in group A (that consisted of one non-fatal PE and one asymptomatic distal DVT) and one VTE complication $(0.8 \%$; $95 \%$ CI, $0.4-5.3 \%)$ in group B (that consisted of one symptomatic proximal DVT) $\left(\chi^{2}\right.$ test, $\left.p=n s\right)$. No other thrombotic complications occurred after hospital discharge during the follow-up period. Eight patients in group A
$(6.1 \%$; $95 \%$ CI, 2.9-12.1\%) and six patients in group B (5\%; $95 \%$ CI, 2.1-11.1\%) showed major or clinically relevant non-major bleeding ( $\chi^{2}$ test, $p=\mathrm{ns}$ ). Major and unusual bleeding occurred in $11 / 169$ cases $(6.5 \%$; $95 \%$ CI $0.2-6.0 \%)$ in gastric bypass-operated patients and in $3 / 81$ cases $(3.7 \%)$ in other types of surgery ( $\chi^{2}$ test, $\left.p=\mathrm{ns}\right)$. The number of cases of major and unusual bleeding amounted to $7(4.6 \%)$ and $7(7.3 \%)$, respectively, in patients with $\mathrm{BMI} \leq 45$ and $>45 \mathrm{~kg} / \mathrm{m}^{2}$ (test $\chi^{2}, p=\mathrm{ns}$ ). Table 4 shows the results of a multiple comparison test between adverse events, type of surgery and treatment groups. The small number of events does not allow multivariate analysis.

No statistically significant differences were found between the two groups regarding the incidence of adverse events (Table 4); there was one case of thrombocytopenia in each group, and there were no cases of HIT. During the treatment and follow-up period, no patients died.

\section{Discussion}

The appropriate prophylactic dosage of anticoagulation for VTE prevention in patients undergoing bariatric surgery is still a matter of debate [2].

In this study, we compared the efficacy and safety of two different fixed doses of parnaparin in a series of 258 bariatric patients. The results of our randomised, pilot trial suggest that a standard prophylactic dose of

Table 1 Baseline characteristics of patients and bariatric procedures per treatment group

\begin{tabular}{|c|c|c|c|c|}
\hline & $\begin{array}{l}\text { Group A } \\
n=131(\%)\end{array}$ & $\begin{array}{l}\text { Group B } \\
n=119(\%)\end{array}$ & $\begin{array}{l}\text { All patients } \\
n=250(\%)\end{array}$ & $p$ value \\
\hline \multicolumn{5}{|l|}{ Sex } \\
\hline Female & $106(80.9)$ & $93(78.2)$ & 199 (79.6) & \multirow[t]{2}{*}{$\mathrm{ns}^{\mathrm{b}}$} \\
\hline Male & $25(19.1)$ & $26(21.8)$ & $51(20.4)$ & \\
\hline Age (years) ${ }^{\mathrm{a}}$ & $40.3 \pm 9.6(18-64)$ & $41.5 \pm 9.9(18-63)$ & $40.9 \pm 9.7(18-64)$ & \multirow[t]{3}{*}{$\mathrm{ns}^{\mathrm{c}}$} \\
\hline Female & $40.6 \pm 8.9$ & $42.1 \pm 9.7$ & $41.3 \pm 9.3$ & \\
\hline Male & $39.3 \pm 12.0$ & $39.2 \pm 10.4$ & $39.3 \pm 11.1$ & \\
\hline $\operatorname{BMI}\left(\mathrm{kg} / \mathrm{m}^{2}\right)^{\mathrm{a}}$ & $44.6 \pm 5.4(36.1-58.8)$ & $44.2 \pm 5.4(36.2-64.1)$ & $44.4 \pm 5.4(36.1-64.1)$ & $\mathrm{ns}^{\mathrm{b}}$ \\
\hline \multicolumn{5}{|l|}{ Surgery } \\
\hline Laparoscopic gastric bypass & $85(64.9)$ & $84(70.6)$ & $169(67.6)$ & \\
\hline Laparoscopic gastric banding & $12(9.2)$ & $9(7.6)$ & $21(8.4)$ & \\
\hline Biliopancreatic diversion & $15(11.5)$ & $9(7.6)$ & $24(9.6)$ & \\
\hline Vertical gastroplasty & $1(0.8)$ & - & $1(0.4)$ & \\
\hline Laparoscopic sleeve gastrectomy & $11(8.4)$ & $11(9.2)$ & $22(8.8)$ & \\
\hline Other & $7(5.3)$ & $6(5.0)$ & $13(5.2)$ & \\
\hline Operating time (min, mean $\pm \mathrm{SD}$ ) & $176 \pm 69$ & $187 \pm 60$ & $181 \pm 64$ & $\mathrm{~ns}^{\mathrm{b}}$ \\
\hline
\end{tabular}


Table 2 VTE risk factors and concomitant pathology
The two groups are not significantly different in terms of frequency of risk factors and incidence of comorbidities ( $\chi^{2}$ test, $T=\mathrm{ns}$ )

\begin{tabular}{|c|c|c|c|}
\hline & $\begin{array}{l}\text { Group A } \\
\text { Parnaparin } \\
4,250 \mathrm{IU}(n=131)\end{array}$ & $\begin{array}{l}\text { Group B } \\
\text { Parnaparin } \\
6,400 \text { IU }(n=119)\end{array}$ & $\begin{array}{l}\text { All patients } \\
(n=250)\end{array}$ \\
\hline Varicose veins, surgery for varicose veins & $7(5.3 \%)$ & $12(10.1 \%)$ & $19(7.6 \%)$ \\
\hline Previous deep vein thrombosis & 1 & - & $1(0.4 \%)$ \\
\hline Previous pulmonary embolism & - & - & - \\
\hline Major surgery in last 3 months & - & - & - \\
\hline $\begin{array}{l}\text { Previous immobilisation }>7 \text { days in the } \\
\text { last month }\end{array}$ & - & - & - \\
\hline Previous myocardial infarction & 1 & 1 & $2(0.8 \%)$ \\
\hline Previous stroke & 1 & - & $1(0.4 \%)$ \\
\hline Smoking & $29(22.1 \%)$ & $32(26.9 \%)$ & $61(24.4 \%)$ \\
\hline Heart failure & - & $4(3.4 \%)$ & $4(1.6 \%)$ \\
\hline Respiratory failure & $10(7.6 \%)$ & $16(13.4 \%)$ & $26(10.4 \%)$ \\
\hline Paralysis & - & - & - \\
\hline Progestin replacement or contraceptive therapy & $10(7.6 \%)$ & $7(5.9 \%)$ & $17(6.8 \%)$ \\
\hline Other risk factors & $6(4.6 \%)$ & $2(17 \%)$ & $8(3.2 \%)$ \\
\hline Diabetes mellitus & $14(10.7 \%)$ & $20(16.8 \%)$ & $34(13.6 \%)$ \\
\hline Arterial hypertension & $48(36.6 \%)$ & $44(37.0 \%)$ & $92(36.8 \%)$ \\
\hline Ischemic cardiomyopathy & $2(1.5 \%)$ & $2(1.7 \%)$ & $4(1.6 \%)$ \\
\hline Rheumatic diseases & $27(20.6 \%)$ & $32(26.9 \%)$ & $59(23.6 \%)$ \\
\hline Chronic obstructive pulmonary disease & $16(12.2 \%)$ & $20(16.8 \%)$ & $36(14.4 \%)$ \\
\hline Peripheral arterial disease & - & $3(2.5 \%)$ & $3(1.2 \%)$ \\
\hline Chronic liver disease & $2(1.5 \%)$ & $6(5.0 \%)$ & $8(3.2 \%)$ \\
\hline Renal failure & $2(1.5 \%)$ & $1(0.8 \%)$ & $3(1.2 \%)$ \\
\hline Other diseases & $5(3.8 \%)$ & $8(6.7 \%)$ & $13(5.2 \%)$ \\
\hline
\end{tabular}

parnaparin $(4,250 \mathrm{IU} /$ day; group $\mathrm{A})$ is as effective as a higher intermediate dose (6,400 IU/day; group B), with similar bleeding rates. During the treatment period, there was an incidence of the primary efficacy endpoint (composite of symptomatic and asymptomatic DVT, PE and death from any case) of $1.5 \%$ in group $\mathrm{A}$ as compared with $0.8 \%$ in group B (test $\chi^{2}, p=\mathrm{ns}$ ). The primary safety outcome of major and clinically relevant non-major bleeding was observed in $6.1 \%$ of patients in group $\mathrm{A}$ and in $5 \%$ of patients in group $\mathrm{B}$, respectively, the rate of adverse events being similar in the two groups of treatment. Our observations are consistent with those of other trials evaluating the efficacy and safety of LMWH in bariatric surgery, in which rates of VTE were 0.1 to $1.1 \%$ and the corresponding rates of bleeding complications were 1.8 to $5.9 \%[8-11,14,18,25]$. The low incidence of thrombotic events recorded in our study and the lack of correlation with dose is presumably due to high rate of patients receiving mechanical prophylaxis in addition to pharmacological prophylaxis $(89.6 \%$ elastic stockings, $96.4 \%$ early deambulation and $62 \%$ intermittent pneumatic compression, respectively).

Our results add interesting information about the optimal anticoagulation dose for VTE prevention in bariatric surgery, since very few studies have compared different doses of heparin in this clinical setting. Scholten evaluated safety and efficacy of two different doses of enoxaparin $(30 \mathrm{mg}$ twice daily, group I; $40 \mathrm{mg}$ twice daily, group II) in a non-randomised study involving 481 patients undergoing primary and revisional bariatric surgery [8]. There were a total of $5.4 \%$ VTE events in group I and $0.6 \%$ in group II, with a similar incidence of bleeding complications; in conclusion, enoxaparin $40 \mathrm{mg}$ twice daily reduced thrombotic complications when compared with enoxaparin $30 \mathrm{mg}$, without an increase in hemorrhage risk. Kalfarentzos randomised 60 consecutive patients undergoing Roux-en-Y gastric bypass to receive either 5, 700 or 9,500 IU of nadroparin [9]. The lower dose did not increase the risk of post-operative thrombotic disease, while coagulation parameters were similar with both doses in all post-operative analyses, including the 3- and 6month follow-up. Importantly, there were no bleeding events in the 5,700-IU group compared with two with the higher dose, suggesting that the lower dose should be considered for the prophylaxis of VTE in bariatric surgical patients. In a prospective open trial, 223 patients undergoing Roux-en- $Y$ gastric bypass were assigned to receive enoxaparin $40 \mathrm{mg}$ (BMI $\left.\leq 50 \mathrm{~kg} / \mathrm{m}^{2} ; n=124\right)$ or 
Table 3 Type and duration of prophylaxis

\begin{tabular}{llll}
\hline & $\begin{array}{l}\text { Group A } \\
\text { Parnaparin } \\
4,250 \mathrm{IU}(n=131)\end{array}$ & $\begin{array}{l}\text { Group B } \\
\text { Parnaparin } \\
6,400 \mathrm{IU}(n=119)\end{array}$ & $\begin{array}{l}\text { All patients } \\
(n=250)\end{array}$ \\
\hline $\begin{array}{l}\text { Total duration of prophylaxis with low } \\
\text { molecular weight heparin (in days) }^{\mathrm{a}}\end{array}$ & $14.1 \pm 2.4(1-15)$ & $14.0 \pm 2.5(2-15)$ & $14.1 \pm 2.4(1-15)$ \\
Muscle electrostimulation during surgery $^{\mathrm{b}}$ & 1 & 2 & 3 \\
Intermittent pneumatic compression (IPC) $^{\mathrm{b}}$ & $79(60.3 \%)$ & $76(63.9 \%)$ & $155(62.0 \%)$ \\
Elastic stockings (ES) $^{\mathrm{b}}$ & $116(88.5 \%)$ & $108(90.8 \%)$ & $224(89.6 \%)$ \\
Early deambulation (ED) $^{\mathrm{b}}$ & $126(96.2 \%)$ & $115(96.6 \%)$ & $241(96.4 \%)$ \\
Heparin alone & $2(1.5 \%)$ & $2(1.7 \%)$ & $4(1.6 \%)$ \\
Heparin + IPC & - & - & - \\
Heparin + ES & $3(2.3 \%)$ & $2(1.7 \%)$ & $5(2.0 \%)$ \\
Heparin + ED & $10(7.6 \%)$ & $6(5.0 \%)$ & $16(6.4 \%)$ \\
Heparin + IPC +ED & $3(2.3 \%)$ & $3(2.5 \%)$ & $6(2.4 \%)$ \\
Heparin + ES +ED & $37(28.2 \%)$ & $32(26.9 \%)$ & $69(27.6 \%)$ \\
Heparin + IPC +ES + ED & $76(58.0 \%)$ & $74(62.2 \%)$ & $150(60.0 \%)$ \\
\hline
\end{tabular}

$60 \mathrm{mg}\left(\mathrm{BMI}>50 \mathrm{~kg} / \mathrm{m}^{2}, \quad n=99\right)$ every $12 \mathrm{~h}$ during hospitalisation and once daily for 10 days after discharge [18]. The anti-Xa levels were monitored serially, and dose adjustments were made for results outside the target prophylactic range $(0.2-0.4 \mathrm{IU} / \mathrm{mL})$ after the third dose. One patient developed non-fatal VTE $(0.45 \%)$ and four patients required transfusion for major bleeding (1.79\%).

Our results are also consistent with those reported in three recently published studies on the pharmacodynamic activity of LMWHs in bariatric patients [26-28]. In a study of 66 patients undergoing surgery for severe obesity, Imberti and colleagues showed that a fixed prophylactic dose of parnaparin (4,250 IU/day) was able to achieve

Table 4 Incidence of bleeding and adverse events

\begin{tabular}{llll}
\hline & $\begin{array}{l}\text { Group A } \\
\text { Parnaparin } \\
4,250 \mathrm{IU} \\
(n=131)\end{array}$ & $\begin{array}{l}\text { Group B } \\
\text { Parnaparin } \\
6,400 \mathrm{IU} \\
(n=119) .\end{array}$ & $\begin{array}{l}\text { All patients } \\
(n=250)\end{array}$ \\
\hline $\begin{array}{l}\text { Major or clinical relevant } \\
\text { bleeding }\end{array}$ & $8 / 131(6.1 \%)$ & $6 / 119(5 \%)$ & $14 / 250(5.6 \%)$ \\
Gastric bypass & $7 / 85(8.2 \%)$ & $4 / 84(4.8 \%)$ & $11 / 169(6.5 \%)$ \\
Other surgery & $1 / 46(2.2 \%)$ & $2 / 35(5.7 \%)$ & $3 / 81(3.7 \%)$ \\
Transfusions (patients) & 4 & 3 & 7 \\
No. of units of blood & & & \\
Intra-op., 1 unit & 1 & - & 1 \\
No. of units of blood & & & 3 \\
Post-op., 1 unit & 1 & 2 & 3 \\
2 units & 2 & 1 & - \\
3 units & - & - & 2 \\
4 units & 1 & - & 1 \\
Thrombocytopenia & 1 & &
\end{tabular}

prophylactic anti-Xa levels in $98.3 \%$ of patients, while a higher dosage $(6,400$ IU/day) was associated with excessive anti-Xa levels in $62.3 \%$ of patients [26]. Forestieri and co-workers demonstrated in a small series of ten severely obese patients (BMI $>50 \mathrm{~kg} / \mathrm{m}^{2}$ ) that doses of both 4,250 and $6,400 \mathrm{IU} /$ day of parnaparin may provide effective prophylaxis for VTE in the perioperative period; the authors speculated that higher doses, which may be associated with higher rates of bleeding complications, would offer no real improvement in efficacy [27]. In the non-randomised study by Simone and colleagues, patients undergoing laparoscopic bariatric surgery received enoxaparin 40 or $60 \mathrm{mg}$ every $12 \mathrm{~h}$ [28]. No supratherapeutic anti-Xa concentrations were observed in the 40-mg group, whereas $57 \%$ of the third dose levels in the 60-mg group were supratherapeutic.

Our results indicate that the standard prophylactic dose of parnaparin may be sufficient for VTE prevention in bariatric surgery, suggesting that higher doses are not necessary in this clinical setting. This finding is in agreement with the results of two studies assessing therapeutic doses of dalteparin [29] and a prophylactic dose of nadroparin [30] or enoxaparin [31] in obese patients and is in contrast with the results of other studies $[8,32]$ that suggested the need to adjust the dosage of LMWH according to body weight.

This study has some limitations. First, because of the small sample size, the results of our trial must be interpreted with caution; any conclusions cannot be definitively drawn and are only hypothesis generating. However, this is, to our knowledge, the largest randomised clinical study comparing two different dosages of LMWH in bariatric surgery ever published; moreover, the practical difficulties associated with obtaining suitable patients in this clinical setting make our 
results, albeit limited and preliminary, of interest. Moreover, a non-inferiority large-scale clinical trial seems not easily feasible because of the very large sample size; using the results of our pilot study and considering VTE events (with an event rate in the two groups of $1.5 \%$ and non-inferiority margin of $0.7 \%$ ) as the primary efficacy outcomes, the calculated sample size is 3,729 patients for group (alpha $=0.05$ and $80 \%$ power), and if we considered as primary outcome the composite incidence of major bleeding and clinically relevant non-major bleeding (with event rate of $6.1 \%$, non-inferiority margin of $1.1 \%$, alpha $=0.05$ and $80 \%$ power), the sample size is even higher (5,754 patients for group). Second, since our study has an open design, there are potential randomisation and diagnostic bias. In order to reduce this possibility, a centralised block-balanced randomisation plan was used, stratified by centre, gender and BMI. Moreover, the colour Doppler ultrasound test was performed by clinicians blinded to the dose of parnaparin given to the patients and all the suspected outcome events were adjudicated by a central committee whose members were unaware of any information regarding the patients. Third, the use of colour Doppler ultrasound for the detection of asymptomatic DVT in obese patients is questionable, since given its low sensitivity [33, 34]. On the other hand, a phlebographic study was not feasible and every effort was used when examining each patient, such as compression manoeuvre and coloured and spectral Doppler, to improve the accuracy of the exams as much as possible, and these were repeated where necessary. Fourth, the duration of the study was quite long because recruitment was slower than anticipated in three centres and was stopped in the other three centres as a result of expiration of the study drug.

In conclusion, our pilot study suggests that a dose of 4 , $250 \mathrm{IU} /$ day of parnaparin seems adequate to prevent VTE complications in patients undergoing surgery for morbid obesity. Definitive validation for the daily clinical practice of 4,250 IU/day of parnaparin for VTE prophylaxis in bariatric surgery now should be theoretically confirmed in large randomised controlled trials, even if these studies are not easily feasible (and probably even unfeasible) due to the very large sample size.

Acknowledgments The investigators wish to thank Alfa Wassermann, Italy for supplying the drugs and insurance policy and for supporting this study with an unrestricted educational grant. We acknowledge the help of Patrizio Ferrari, Head of Scientific Operations, Alfa-Wassermann, for technical support.

The sponsor had no role in the design and conduct of the study, management, analysis, interpretation of the data and preparation, review or approval of the manuscript.

Conflict of Interest Davide Imberti, Edoardo Baldini, Matteo Giorgi Pierfranceschi, Alberto Nicolini, Concetto Cartelli, Marco De Paoli, Marcello Boni, Esmeralda Filippucci, Stefano Cariani and Giorgio Bottani state that they have no conflict of interest to declare.
Open Access This article is distributed under the terms of the Creative Commons Attribution License which permits any use, distribution, and reproduction in any medium, provided the original author(s) and the source are credited.

\section{Participating Investigators and Study Sites}

Study Coordinator:

Imberti Davide, Centro Emostasi e Trombosi, Dipartimento di

Medicina, Ospedale G. Da Saliceto, Piacenza, Italy Investigators:

- Baldini Edoardo, Roberta Raselli, Francesca Cattadori, U.O. Chirurgia Generale-Dipartimento di Chirurgia; Imberti Davide, Centro Emostasi e Trombosi, Dipartimento di Medicina; Giorgi Pierfranceschi Matteo, Dipartimento di Emergenza; Ospedale G. Da Saliceto, Piacenza (167 patients)

- Silingardi Mauro, Nicolini Alberto, Centro Emostasi e Trombosi, Medicina I, Della Valle Edoardo, Benassi Rossella, Cartelli Concetto, Chirurgia Generale II, Azienda Ospedaliera S. Maria Nuova, Reggio Emilia (24 patients)

- De Paoli Marco, Chirurgia Generale, Ospedale Galliera, Genova (23 patients)

- Mariani Enrico, Boni Marcello, Chirurgia Generale, Flamini Flaminio Otello, Filippucci Esmeralda U.O. Angiologia, Ospedale San Giovanni Battista, Foligno (Perugia) (14 patients)

- Amenta Enrico, Cariani Stefano, Guerra Manuela, Centro Studi Obesità Patologica, Chirurgia Generale III, Policlinico Sant'Orsola Malpighi, Bologna (12 patients)

- Bottani Giorgio, Zanardi Alberto, Ospedale Civile, Dipartimento di Chirurgia Generale, Mortara (Pavia) (11 patients)

\section{References}

1. DeMaria EJ. Bariatric surgery for morbid obesity. N Engl J Med. 2007;356(21):2176-83. Review. PubMed PMID: 17522401.

2. Gould MK, Garcia DA, Wren SM, et al. Prevention of VTE in nonorthopedic surgical patients: antithrombotic therapy and prevention of thrombosis, 9th edn: American College of Chest Physicians Evidence-Based Clinical Practice Guidelines. Chest. 2012;141(2 Suppl):e227S-77S. Erratum in: Chest.2012 May;141(5):1369. PubMed PMID: 22315263; PubMed Central PMCID: PMC3278061.

3. Sjöström L, Lindroos AK, Peltonen M, et al. Lifestyle, diabetes, and cardiovascular risk factors 10 years after bariatric surgery. N Engl J Med. 2004;351(26):2683-93.

4. Prystowsky JB, Morasch MD, Eskandari MK, et al. Prospective analysis of the incidence of deep venous thrombosis in bariatric surgery patients. Surgery. 2005;138(4):759-63. discussion 763-5. PubMed PMID: 16269306.

5. Rocha AT, de Vasconcellos AG, da Luz Neto ER, et al. Risk of venous thromboembolism and efficacy of thromboprophylaxis in hospitalized obese medical patients and in obese patients undergoing bariatric surgery. Obes Surg. 2006;16(12):1645-55. Review. PubMed PMID: 17217642.

6. Stroh C, Birk D, Flade-Kuthe R, et al. Evidence of thromboembolism prophylaxis in bariatric surgery - results of a quality assurance trial in bariatric surgery in Germany from 2005 to 2007 and review of the literature. Obes Surg. 2009; 19(7):928-36. 
7. Gonzalez QH, Tishler DS, Plata-Munoz JJ, et al. Incidence of clinically evident deep venous thrombosis after laparoscopic Rouxen-Y gastric bypass. Surg Endosc. 2004;18(7):1082-4. PubMed PMID: 15156394.

8. Scholten DJ, Hoedema RM, Scholten SE. A comparison of two different prophylactic dose regimens of low molecular weight heparin in bariatric surgery. Obes Surg. 2002;12(1):19-24. PubMed PMID: 11868291.

9. Kalfarentzos F, Stavropoulou F, Yarmenitis S, et al. Prophylaxis of venous thromboembolism using two different doses of low-molecularweight heparin (nadroparin) in bariatric surgery: a prospective randomized trial. Obes Surg. 2001;11(6):670-6. PubMed PMID: 11775562.

10. Hamad GG, Choban PS. Enoxaparin for thromboprophylaxis in morbidly obese patients undergoing bariatric surgery: findings of the prophylaxis against VTE outcomes in bariatric surgery patients receiving enoxaparin (PROBE) study. Obes Surg. 2005;15(10): 1368-74. PubMed PMID: 16354513.

11. Kothari SN, Lambert PJ, Mathiason MA. Best Poster Award. A comparison of thromboembolic and bleeding events following laparoscopic gastric bypass in patients treated with prophylactic regimens of unfractionated heparin or enoxaparin. Am J Surg. 2007;194(6):709-11. PubMed PMID: 18005758.

12. Raftopoulos I, Martindale C, Cronin A, et al. The effect of extended post-discharge chemical thromboprophylaxis on venous thromboembolism rates after bariatric surgery: a prospective comparison trial. Surg Endosc. 2008;22(11):2384-91. PubMed PMID: 18622558.

13. Magee CJ, Barry J, Javed S, et al. Extended thromboprophylaxis reduces incidence of postoperative venous thromboembolism in laparoscopic bariatric surgery. Surg Obes Relat Dis. 2010;6(3):3225. PubMed PMID: 20510295.

14. Cotter SA, Cantrell W, Fisher B, et al. Efficacy of venous thromboembolism prophylaxis in morbidly obese patients undergoing gastric bypass surgery. Obes Surg. 2005;15(9):1316-20. PubMed PMID: 16259895.

15. Hirsh J, Raschke R. Heparin and low-molecular-weight heparin: the Seventh ACCP Conference on Antithrombotic and Thrombolytic Therapy. Chest. 2004;126(3 Suppl):188S-203S. PubMed PMID: 15383472.

16. Geerts WH, Bergqvist D, Pineo GF, et al. Prevention of venous thromboembolism: American College of Chest Physicians EvidenceBased Clinical Practice Guidelines (8th edition). Chest. 2008;133 (6 Suppl):381S-453S. PubMed PMID: 18574271.

17. Planès A, Samama MM, Lensing AW, et al. Prevention of deep vein thrombosis after hip replacement-comparison between two lowmolecular heparins, tinzaparin and enoxaparin. Thromb Haemost. 1999;81(1):22-5. PubMed PMID: 10348714.

18. Borkgren-Okonek MJ, Hart RW, Pantano JE, et al. Enoxaparin thromboprophylaxis in gastric bypass patients: extended duration, dose stratification, and antifactor Xa activity. Surg Obes Relat Dis. 2008;4(5):625-31. PubMed PMID: 18261965.

19. Simoneau MD, Vachon A, Picard F. Effect of prophylactic dalteparin on anti-factor Xa levels in morbidly obese patients after bariatric surgery. Obes Surg. 2010;20(4):487-91. PubMed PMID: 18931882.

20. Lim W. Using low molecular weight heparin in special patient populations. J Thromb Thrombolysis. 2010;29(2):233-40. PubMed PMID: 19902146.
21. Rowan BO, Kuhl DA, Lee MD, et al. Anti-Xa levels in bariatric surgery patients receiving prophylactic enoxaparin. Obes Surg. 2008;18(2):162-6. PubMed PMID: 18165884.

22. Sanderink GJ, Le Liboux A, Jariwala N, et al. The pharmacokinetics and pharmacodynamics of enoxaparin in obese volunteers. Clin Pharmacol Ther. 2002;72(3):308-18. PubMed PMID: 12235452.

23. McKeage K, Keating GM. Parnaparin: a review of its use in the management of venous thromboembolism, chronic venous disease and other vascular disorders. Drugs. 2008;68(1):105-22. PubMed PMID: 18081375.

24. Linkins LA, Dans AL, Moores LK, et al. Treatment and prevention of heparin-induced thrombocytopenia: antithrombotic therapy and prevention of thrombosis, 9th edn: American College of Chest Physicians Evidence-Based Clinical Practice Guidelines. Chest. 2012;141(2 Suppl):e495S-530S. doi:10.1378/ chest.11-2303. PubMed PMID: 22315270; PubMed Central PMCID: PMC3278058.

25. Becattini C, Agnelli G, Manina G, et al. Venous thromboembolism after laparoscopic bariatric surgery for morbid obesity: clinical burden and prevention. Surg Obes Relat Dis. 2012;8(1):108-15. PubMed PMID: 22014482.

26. Imberti D, Legnani C, Baldini E, et al. Pharmacodynamics of low molecular weight heparin in patients undergoing bariatric surgery: a prospective, randomised study comparing two doses of parnaparin (BAFLUX study). Thromb Res. 2009;124(6):667-71. PubMed PMID: 19482341.

27. Forestieri P, Quarto G, De Caterina M, et al. Prophylaxis of thromboembolism in bariatric surgery with parnaparin. Obes Surg. 2007;17(12):1558-62. PubMed PMID: 18004632.

28. Simone EP, Madan AK, Tichansky DS, et al. Comparison of two lowmolecular-weight heparin dosing regimens for patients undergoing laparoscopic bariatric surgery. Surg Endosc. 2008;22(11):2392-5. PubMed PMID: 18594915.

29. Wilson SJ, Wilbur K, Burton E, et al. Effect of patient weight on the anticoagulant response to adjusted therapeutic dosage of low-molecular-weight heparin for the treatment of venous thromboembolism. Haemostasis. 2001;31(1):42-8. PubMed PMID: 11408748.

30. Heizmann M, Baerlocher GM, Steinmann F, et al. Anti-Xa activity in obese patients after double standard dose of nadroparin for prophylaxis. Thromb Res. 2002;106(4-5):179-81. PubMed PMID: 12297122

31. Brasileiro AL, Miranda Jr F, Ettinger JE, et al. Incidence of lower limbs deep vein thrombosis after open and laparoscopic gastric bypass: a prospective study. Obes Surg. 2008;18(1):52-7. PubMed PMID: 18080727.

32. Handeland GF, Abildgaard U, Holm HA, et al. Dose adjusted heparin treatment of deep venous thrombosis: a comparison of unfractionated and low molecular weight heparin. Eur J Clin Pharmacol. 1990;39(2):107-12. PubMed PMID: 2174783.

33. Kearon C, Julian JA, Newman TE, et al. Noninvasive diagnosis of deep venous thrombosis. McMaster Diagnostic Imaging Practice Guidelines Initiative. Ann Intern Med. 1998;128(8):663-77. Erratum in: Ann Intern Med 1998 Sep 1;129(5):425. PubMed PMID: 9537941.

34. Kearon C. Noninvasive diagnosis of deep vein thrombosis in postoperative patients. Semin Thromb Hemost. 2001;27(1):3-8. PubMed PMID: 11288945. 